\title{
Electrostatic spray deposition (ESD) of polymeric powders on thermoplastic (PA66) substrate
}

\author{
M. Barletta*, A. Gisario, V. Tagliaferri \\ University of Rome "Tor Vergata", Dipartimento di Ingegneria Meccanica, Via del Politecnico, 1 - 00133 Rome, Italy
}

Received 27 July 2005; accepted in revised form 18 November 2005

Available online 5 January 2006

\begin{abstract}
This paper deals with a primerless electrostatic spray deposition process (ESD) for coating thermoplastic (PA66) substrates using epoxypolyester, metallic epoxy-polyester, and epoxy powder paint. A novel and never before used pretreatment system, based on a low speed cold spray of fine copper powders, applied a thin conductive film on the plastic substrate, which made the ESD possible.

The focus of first part of the paper is on analyzing the influence of both electrical and aerodynamic process parameters on ESD process. Differences in behavior of the powders used were evident. Design of experiments (DOE) was used to plan experimental trials and related ANOVA tables were made and used as support instruments to interpret the experimental findings, process modeling, and to the understand physical phenomena involved in the deposition process. As a result, several process maps were produced in which consistent trends of coating thickness and average roughness vs. operative parameters are reported. Careful qualification of the polymeric films was also carried out using the most relevant performance indicators.

The second part of the paper focuses on assessing the influence of exposure time on coating thickness and average roughness of the polymeric films, that is, once the electrical and aerodynamic parameters had been optimized.
\end{abstract}

(C) 2005 Elsevier B.V. All rights reserved.

Keywords: Coating; Electrostatic spray deposition; Cold spray; Thermoplastic substrate

\section{Introduction}

Plastic components are painted for aesthetic and functional reasons. In manufacturing of outdoor components, paints are designed to give surface properties like abrasion resistance, impact strength and good behaviour under most part of weathering and chemical attacks [1]. In interior applications, paints are employed to improve appearance, allowing the improvement of surface gloss, scratch and fluorescence light resistance [2]. In-line painting processes are commonly used to paint plastic components, and solvent-based products are typically selected for most of its applications [1-3]. The process sequence of in-line painting involves phosphatation/E-coat, followed by undercoating, and finally the topcoat application. Curing or drying cycles are often required after each phase of the painting process. In addition to cleaning and washing, a large

\footnotetext{
* Corresponding author.

E-mail address: barletta@mail.mec.uniroma2.it (M. Barletta).
}

range of prepaint treatments exists [2]. Surface activation processes such as flaming, low plasma spray, or corona are widely used for plastic components as they boost the polarity of polymers with low surface polarity thereby securing paint adhesion [4,5]. Furthermore, a conductive flexible primer is always applied on the plastic surface to ensure good adhesion between the topcoat and substrate, to make electrostatic paint application possible, and to prevent cracks nucleating in the brittle topcoats and propagating into the plastic substrate [5]. Furthermore, the employment of fillers inside the 'as mould' plastic components is also becoming more common as it make them conductive and suitable for ESD [6,7]. In almost all cases, the coatings are applied electrostatically after prepaint treatments, with manual spraying to correct uncovered areas or coating defects and anomalies.

Even if the best performance in terms of aesthetic and functional properties of coatings can be achieved using solventbased paint facilities [3], there are still significant drawbacks connected to the considerable amount of solvent emitted during 
a standard in-line painting process [3]. Strong environmental movements are promoting and increasing awareness of alternative painting solutions such as using water-based or high solids content paints, primerless paint operations, and even powder coating to significantly reduce overall environmental impact. Furthermore, the idea that optimizing operational settings of painting process could improve process effectiveness and result in significant savings and less serious environmental impacts is becoming increasingly popular.

In this respect, this paper deals with an application of a primerless electrostatic spray deposition process (ESD) to coat thermoplastic (PA66) substrates with epoxy-polyester, metallic epoxy-polyester, and epoxy powder paint. A novel and never previously used pretreatment system, based on a low speed cold spray of fine copper powders was used to apply thin copper films onto the plastic substrates, hence reducing surface resistivity, providing a surface on which ESD works, and ensuring the best adhesion of topcoat. Moreover, process analysis of ESD was developed in order to identify the most influential process parameters and their best operational ranges. An analysis of coating performance according to exposure time was also performed. Design of experiments (DOE) was employed to schedule the experimental campaign. A statistical approach was also used as a useful support to interpreting the experimental findings, to aid process modeling, and to understand physical phenomena involved in deposition process. As a result, several process maps were made which report consistent trends of coating thickness and average roughness vs. operative parameters, with the aim of providing manufacturers with practical recommendations and stimulating insights on how to get the most from using the powder coating process on thermoplastic components. The most significant performance indicators of the polymeric film on plastic substrates were also identified and estimated. These performance indicators include coating thickness and uniformity, surface finishing (roughness), the aesthetic aspect (morphology), and adhesion (scratch resistance).

\section{Experimental}

\subsection{Materials}

Polyamide (PA66) was chosen for use as thermoplastic substrate. $60 \times 40 \times 2 \mathrm{~mm}^{3}$ slabs were cut from $2 \times 1 \mathrm{~m}^{2}$ extruded sheets made from PA66 by fine blanking so that even the slightest bending or distortions in workpieces would be avoided. PA66 properties are reported in Table 1.

Three types of polymeric powders, $20-25 \mu \mathrm{m}$ as average particle size and 0.95 as factor shape, were used: a hybrid epoxy-polyester, a hybrid epoxy-polyester with metallic flakes, and an epoxy. They are characterized by a dielectric constant close to 3 and a surface resistivity in the range of $10^{11}$ $10^{14} \Omega$ /square. Copper powders (99.5\% wt), less than $20 \mu \mathrm{m}$ as average particle size and 0.67 as factor shape, were used as raw material to pretreat the polyamide (PA66) substrate. The properties of polymeric and copper powders can be found in the technical literature.
Table 1

Properties of the polyamide (PA66) substrate

\begin{tabular}{|c|c|c|c|}
\hline $\begin{array}{l}\text { General and electrical } \\
\text { properties }\end{array}$ & S.I. & Thermal properties & S.I. \\
\hline Density, $\mathrm{kg} / \mathrm{m}^{3}$ & 1100 & $\begin{array}{l}\mathrm{CTE} \text {, linear } 20^{\circ} \mathrm{C} \text {, } \\
\mu \mathrm{m} / \mathrm{m}{ }^{\circ} \mathrm{C}\end{array}$ & $\sim 65$ \\
\hline Water absorption, $\%$ & $\sim 2.5 \%$ & $\begin{array}{l}\mathrm{CTE} \text {, linear } 100^{\circ} \mathrm{C} \text {, } \\
\mu \mathrm{m} / \mathrm{m}{ }^{\circ} \mathrm{C}\end{array}$ & $\sim 100$ \\
\hline $\begin{array}{l}\text { Electrical } \\
\quad \text { resistivity, } \Omega \mathrm{cm}\end{array}$ & $\sim 10^{14}$ & $\begin{array}{l}\text { Thermal conductivity, } \\
\mathrm{W} / \mathrm{m} \mathrm{K}\end{array}$ & $\sim 0.27$ \\
\hline $\begin{array}{l}\text { Surface } \\
\quad \text { resistance, } \Omega\end{array}$ & $\sim 5 * 10^{12}$ & Melting point, ${ }^{\circ} \mathrm{C}$ & $\sim 260$ \\
\hline Dielectric constant & $\sim 4$ & $\begin{array}{l}\text { Maximum service } \\
\text { temperature, }{ }^{\circ} \mathrm{C}\end{array}$ & $\sim 235$ \\
\hline $\begin{array}{l}\text { Dielectric strength, } \\
\mathrm{kV} / \mathrm{mm}\end{array}$ & $\sim 70$ & $\begin{array}{l}\text { Vicat softening } \\
\text { point, }{ }^{\circ} \mathrm{C}\end{array}$ & $\sim 245$ \\
\hline
\end{tabular}

\subsection{Electrostatic spray deposition}

The electrostatic spray deposition (ESD) system used in this experimentation was composed of a delivery system, a charging system, a powder booth, and a recovery system. The essential parts of the painting facility (Fig. 1) are: the feed hopper (a fluidized bed), the powder spray gun, the electrostatic power source and controls, the booth, the over-sprayed powder collection system, and the powder recovery system. These components are connected by hoses and cables and all the necessary regulators and fittings. A convective oven (model RT11, $11 \mathrm{~kW}$ maximum power) to cure the just adhered film of polymeric powder completes the painting system.

In electrostatic spray deposition (ESD) process, powder coatings are applied onto substrate by spraying an electrically charged cloud of fine powders with an average particle size around $20-25 \mu \mathrm{m}$. This powder is electrostatically charged under high voltage ranging from 30 to $90 \mathrm{kV}$ in a low amperage field (corona charging). Using compressed air for transport, the powder moves from the feed hopper to the tip of a spray-gun. Here, the powder passes along an electrode designed to impart an electrostatic charge to the powder material, which is in fact quickly charged. Due to electric repulsion between charged powder particles, a cloud of fine powder leaves the spray-gun which is directed towards the workpiece using the electrostatic field and aerodynamic push of the outgoing air flow. So, when a grounded workpiece is dipped in the cloud of fine powders, the charged particles, driven by both the electrical and aerodynamic forces, are attracted to the substrate, temporarily adhering to it before the curing process. After application of the powder, the substrate is usually heated in a convection oven, as a result of which the powder starts melting and forms a continuous film. A curing reaction of the liquefied film then causes it to solidify again.

\subsection{Prepaint treatments}

As plastic substrates are intrinsically non-conductive, they cannot be powder coated without specific pretreatment. Plastic substrate can be made to conduct, be semi-conductive, or antistatic. For powder coating operations making plastic substrate 


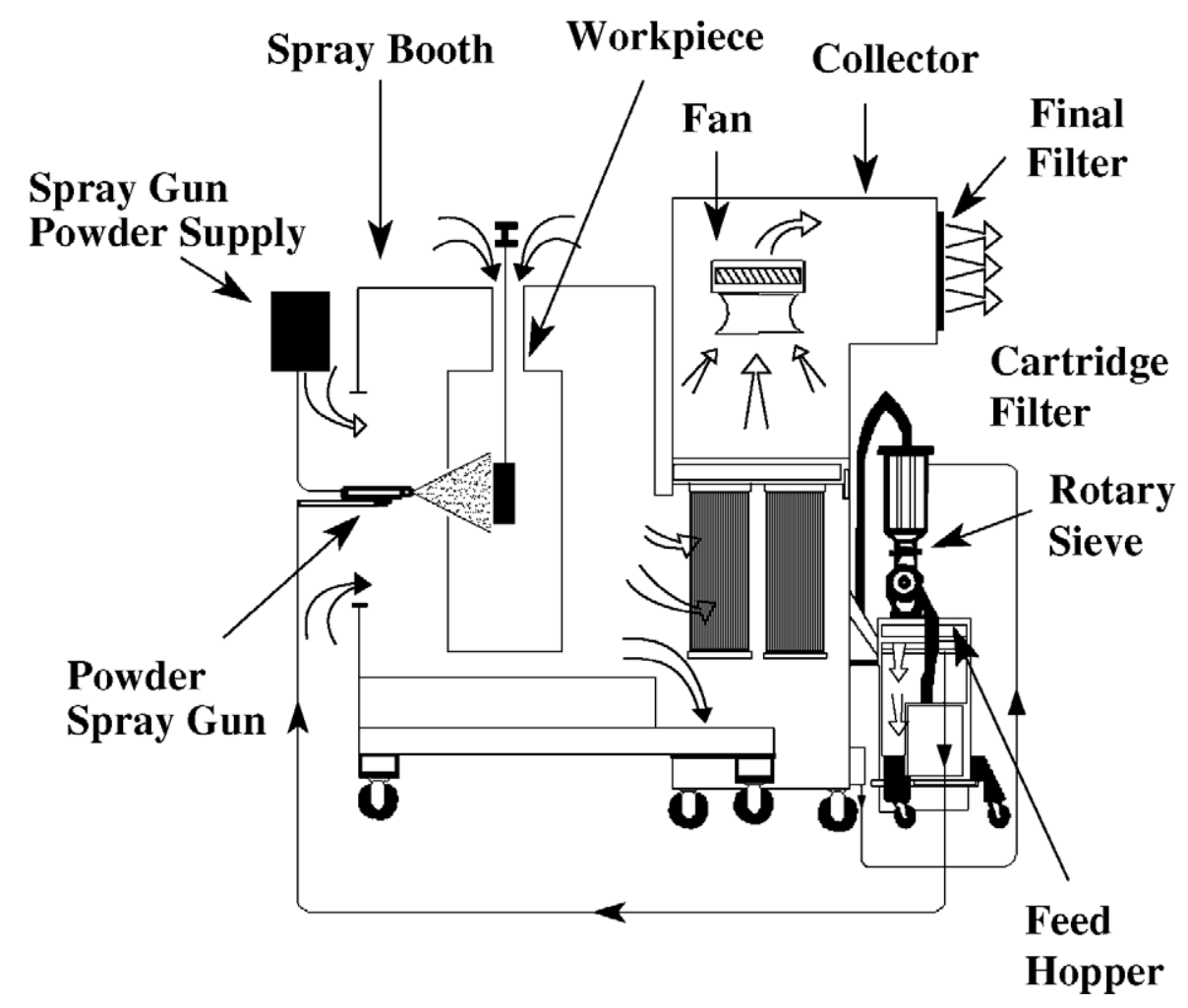

Fig. 1. Electrostatic Spray Deposition (ESD) system.

semi-conductive or, sometimes, only antistatic, is sufficient. In this study, a novel pre-paint treatment based upon a cold spray of copper powders was used to make suitable polyamide (PA66) substrate for electrostatic spray deposition (ESD). The system was very similar to that used for ESD and was composed of a feed hopper (a fluidized bed), a controlled gun, a powder booth, and a powder collection and recovery system. The powders moved from feed hopper through to the tip of the gun under the aerodynamic push of air flow at moderate pressure (in the range of 5-6 bar). After this, the powders were projected toward the polyamide (PA66) substrate for a short exposure time (maximum $120 \mathrm{~s}, 60 \mathrm{~s}$ for each sample face), therefore striking the plastic surface at a moderate impact speed (very close to $5 \mathrm{~m} / \mathrm{s}$ ). This modifies the electrical properties of the plastic substrates without damaging their morphology too much. The powder that bounces back on impact was rescued by the powder collection system and then fed to the hopper by the powder recovery system.

After prepaint treatments and drying, size checks were performed using a Mitutoyo Digital Palmer $( \pm 1 \mu \mathrm{m}$ as accuracy) and, above all, surface resistivity was measured on 100 samples using an Keithley model 6517A electrometer. The surface resistivity was evaluated by taking nine measurements equally spaced over the whole surface of each plastic workpiece. The surface resistivity was taken as the average of all the measurements.

\subsection{Coating process}

The plastic workpieces were grounded before coating using a 'built ad hoc' holder, and positioned inside the powder booth of the electrostatic spray deposition (ESD) system in a fixed position (400 $\mathrm{mm}$ away from the tip of the gun). The environmental conditions were constantly kept under firm control in order to avoid systematic error affecting the experimental data. All the experiments were carried out in under $40 \%$ relative humidity with an average temperature of 20 ${ }^{\circ} \mathrm{C}\left( \pm 0.2{ }^{\circ} \mathrm{C}\right.$ as accuracy). Once the coating was applied onto the substrate, the plastic workpiece was carefully pulled out from the powder booth. Following this, the plastic substrates were placed in the oven, which was preventively heated to $170{ }^{\circ} \mathrm{C}$ to assure the highest heating rate. Consequently, the 'orange peel' surface structure typically generated by powder coating as a result of the liquefaction and subsequent curing process was reduced [2]. The plastic substrates used in the experiments carried out in this study were baked in a convection oven for 15 min to establish the full film properties for which the materials were designed. In addition to the cure, the amount of polymer deposited on the substrates was monitored using a coating thickness gauge (under the regulations ISO 2178 and ISO 2370). Further controls were performed using a Mitutoyo Digital Palmer. Thickness was evaluated by taking nine measurements equally spaced over the entire surface of each plastic workpiece. The coating thickness was taken as the average of all nine measurements. The most important properties of the coated plastic components were also characterized. These measurements included the average coating roughness (using Taylor-Hobson model Intra-Ultra inductive profilometer), surface morphology (Leika model DM IRM optical microscope) and a scratch test to measure adhesion (using a cross hatcher under the regulation ISO 2409). 
Table 2

First 'full factorial' experimental plan for each powder particle [* the feeding pressure (i.e. powder), expressed in bar, used for hybrid epoxy polyester promoted with aluminum flakes is 0.5 bar higher because of higher powder density]

\begin{tabular}{llll}
\hline Levels & \multicolumn{2}{l}{ Experimental factors } \\
\cline { 2 - 4 } & Voltage $(\mathrm{kV})$ & $\begin{array}{l}\text { Feeding pressure, } \\
\text { bar* }\end{array}$ & $\begin{array}{l}\text { Auxiliary pressure, } \\
\text { bar }\end{array}$ \\
\hline I & 30 & 1 & 0.5 \\
II & 50 & 1.5 & 1 \\
III & 70 & 2.0 & 1.5 \\
IV & 90 & & \\
\hline
\end{tabular}

\subsection{Experimental procedure and plans}

A full factorial experimental plan was carried out to establish the process leading mechanisms, to examine the combined effect on coating process of each operative variable, and to identify the best operative process conditions. This full factorial experimental plan used voltage, feeding pressure (related to the amount of powder per unit of time passing through the tip of the gun), and auxiliary pressure (related to the amount of spread the cloud of fine powders outgoing from the tip of the gun has). The settings for these are shown in Table 2. Exposure time in all experiments was set to $6 \mathrm{~s}$. An individual experimental plan was developed for each powder typology chosen as painting material. All the tests were repeated four times to ensure reliability of experimental data. This resulted in a total of 432 trials being carried out. A full statistical approach in reporting and examining experimental data was followed. A general ANOVA linear model was used to support interpretation of the physical mechanisms involved in the deposition process and to establish the significance of operational parameters and their experimental levels.

The best operative windows for each polymeric powder employed were identified as a result of the first experimental plan. This range of best operational windows operative conditions was then chosen as the standardized test condition for second experimental plan (voltage of $50 \mathrm{kV}$, feeding and auxiliary pressure of 2.0 and 1.0 bar, respectively) so that the effect of exposure time on ESD process could be studied. Exposure times ranging from 3 to $15 \mathrm{~s}$ were investigated for each polymeric powder. Moreover, four repetitions for each test condition were executed in order to ensure experimental data reliability. Accordingly, a total of 60 additional trials were performed to trace coating thickness and average roughness trends according to exposure time.

\section{Results and discussion}

\subsection{Cold spray}

The impact of copper powders on plastic substrate during cold spray treatment caused splinter fragmentation and subsequent embedding of $\mathrm{Cu}$ debris and fines in the metal surface. A rapidly growing $\mathrm{Cu}$ thin coating was consequently obtained. Figs. 2 and 3 show optical microscope images of cold

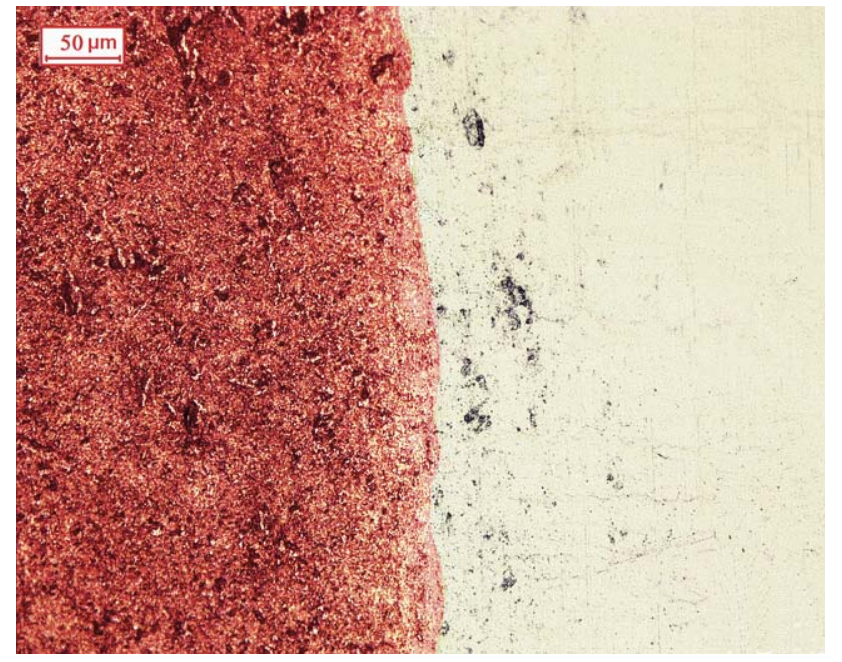

Fig. 2. Copper thin films embedded into plastic (PA66) substrate: interface between treated and untreated surface.

spray coated plastic slabs. A denser and quite compact coating can be seen. No significant wear phenomena were associated with the cold spray process. The digital palmer revealed differences in substrate thickness of under $3 \mu \mathrm{m}$, a value close to the resolution of the instrument, and in any case, acceptable in the light of substrate typology.

Fig. 4 reports the trend in copper mass growth according to cold spray exposure time. A rapid increase of deposited copper metal substrate was exhibited during the first few seconds of the prepaint treatment. After a longer exposure time than $60 \mathrm{~s}$, an asymptotic level of amount of copper was deposited onto plastic substrate. In fact, when the substrate was exposed to a longer cold spray prepaint treatment, only slight increases in mass growth occur. It is therefore possible to formulate a hypothesis of progressive saturation of the external layers of the plastic substrate caused by the copper splinters becoming embedded in the plastic substrate. Accordingly, during the first part of cold

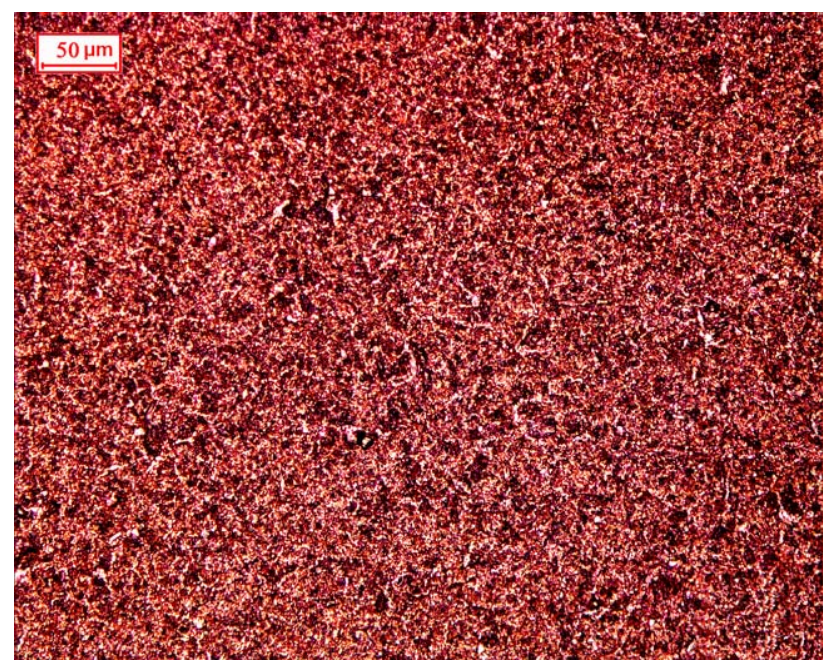

Fig. 3. Copper thin films embedded into plastic (PA66) substrate: surface after an exposure time of $1 \mathrm{~min}$. 

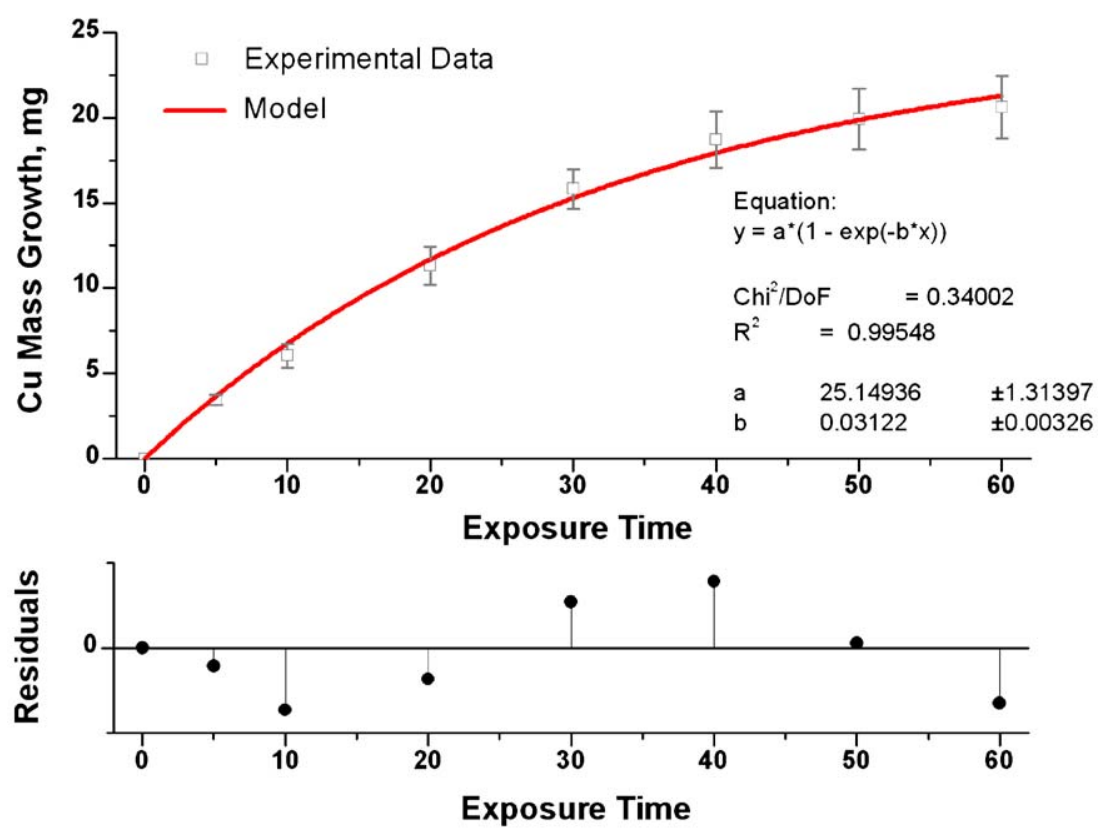

Fig. 4. Copper mass growth vs. cold spray exposure time.

spray prepaint treatment, the plastic substrate was directly submitted to strokes from the copper grains. Since copper powders are much harder than plastic substrate and as they are projected towards the substrate at high speed (about $5 \mathrm{~m} / \mathrm{s}$ ), very fast growth of the copper film was attained. However, after further exposure, the copper powders impacting onto the substrate met with a surface of copper film whose properties are completely different from those of the original plastic substrate. In fact, the copper film already deposited formed a barrier to further deposition of the copper splinters because copper film is considerably harder than the starting plastic substrate. As a result, the deposition process initially slowed down, and was then followed by a negligible increase of deposited copper during lengthy cold spray exposure time (longer than 40-50 s). It is deduced that the copper film already deposited has a self-limiting effect preventing growth of a thicker coating. This mass growth trend and related saturation effect is very similar to that found for low speed cold spray [8] and fast fluidized bed [9] coating process using ceramic powders on metal substrates. Here the rapid increase of film thickness during the initial moments of the coating process was quickly followed by an asymptotic condition [9].

ONCE established, the copper film was found to change the electrical properties of the plastic substrate, making it suitable

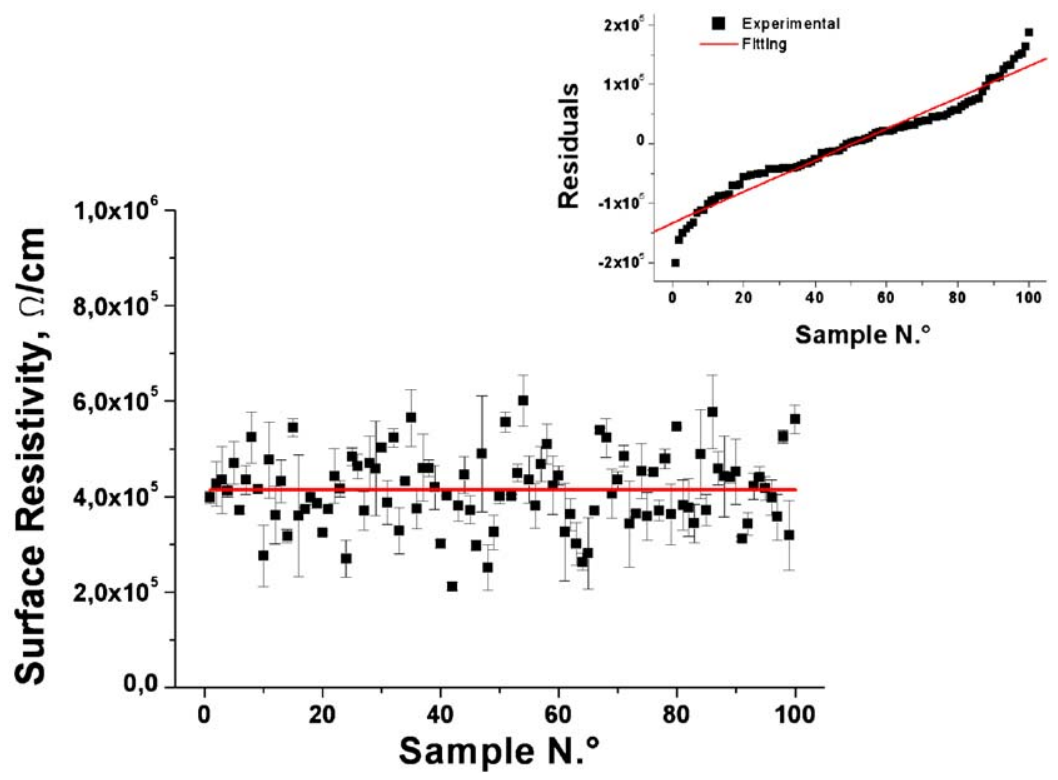

Fig. 5. Surface resistivity of plastic (PA66) substrate after prepaint treatment. 
for electrostatic deposition. The surface resistivity measurements are reported in Fig. 5. Values in the range of $2 \times 10^{5}$ to $7 \times 10^{5} \Omega / \mathrm{cm}$ were measured. These values are very close to typical values of surface resistivity achieved by other techniques typically used to make the plastic substrate semiconductive [2]. Therefore, the embedding of copper splinters onto the external layers of plastic (PA66) substrates made the latter sufficiently semi-conductive to maintain an electrostatic field which discharges the powders when they hit the part during electrostatic coating process so that further powder can be deposited onto the plastic substrate.

\subsection{Electrostatic spray deposition (ESD): analysis of process parameters}

Fig. 6 reports the main effect plots (MEP) of coating thickness and average roughness for all the polymeric powders used. Fig. 6-a displays the MEP of coating thickness
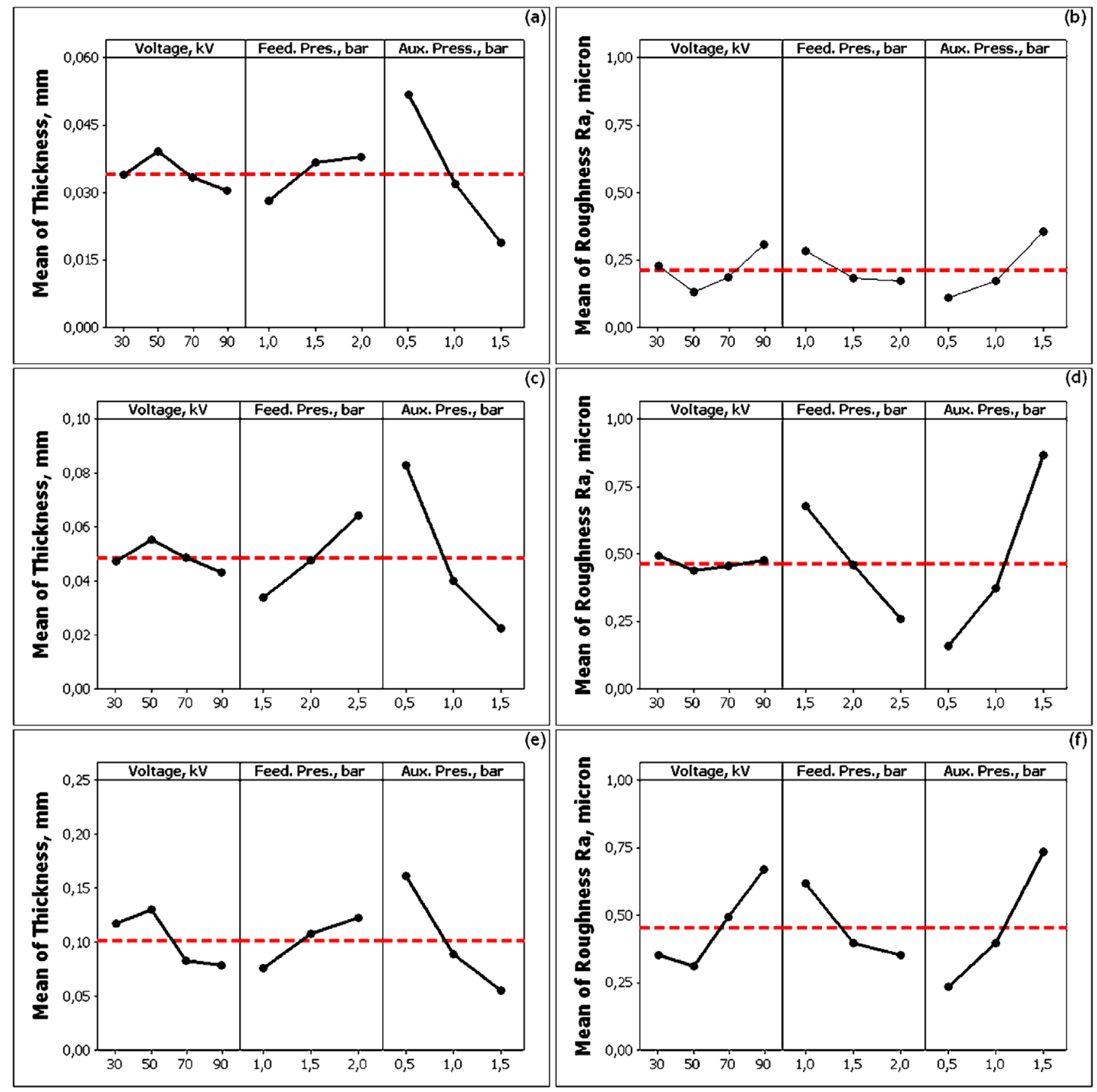

Fig. 6. Main effect plots: (a) coating thickness for epoxy-polyester powder, (b) average roughness for epoxy-polyester powder, (c) coating thickness for epoxypolyester powder with metallic flakes, (d) average roughness for epoxy-polyester powder with metallic flakes, (e) coating thickness for epoxy powder, (f) average roughness for epoxy powder. 
Table 3

ANOVA table for coating thickness for all the deposited films

\begin{tabular}{|c|c|c|c|c|c|c|}
\hline \multirow[t]{2}{*}{ Source } & \multicolumn{2}{|c|}{$\begin{array}{l}\text { Epoxy- } \\
\text { polyester }\end{array}$} & \multicolumn{2}{|c|}{$\begin{array}{l}\text { Metallic } \\
\text { epoxy- } \\
\text { polyester }\end{array}$} & \multicolumn{2}{|l|}{ Epoxy } \\
\hline & $\mathrm{F}$ & $\mathrm{P}$ & $\mathrm{F}$ & $\mathrm{P}$ & $\mathrm{F}$ & $\mathrm{P}$ \\
\hline Voltage, $\mathrm{kV}$ & 2.23 & 0.09 & 1.47 & 0.23 & 7.25 & 0.00 \\
\hline Feed. Pres., bar & 6.31 & 0.00 & 18.72 & 0.00 & 8.63 & 0.00 \\
\hline Aux. Pres., bar & 61.69 & 0.00 & 70.54 & 0.00 & 43.96 & 0.00 \\
\hline Voltage, $\mathrm{kV}^{*}$ Feed. Pres., bar & 1.49 & 0.19 & 0.97 & 0.45 & 0.62 & 0.71 \\
\hline Feed. Pres., bar* Aux. Pres., bar & 0.14 & 0.97 & 2.56 & 0.04 & 1.70 & 0.16 \\
\hline Voltage, kV* Aux. Pres., bar & 1.25 & 0.29 & 1.20 & 0.31 & 1.19 & 0.32 \\
\hline
\end{tabular}

for hybrid epoxy-polyester powder. An increase in voltage from 30 to $50 \mathrm{kV}$ was found to cause a sharp increase in coating thickness. This was ascribed to the connected increase in the electrical field. In fact, under the action of greater electrical forces, the cloud of electrically charged powder was selectively pushed from the tip of the gun toward the grounded plastic substrate, increasing the transfer efficiency of electrostatic spray deposition. Nevertheless, when voltage was increased to $70 \mathrm{kV}$, and ultimately to $90 \mathrm{kV}$, the resulting usually stronger electrical field subsequently meant the copper layer was not able to ground all the electrical charge of incoming polymeric powders when they came into contact with the plastic substrate. This results in a strong repelling effect which causes detachment of just adhered but unconsolidated polymeric powders. So a concurrent decrease in coating thickness was detected. This result agreed with experimental findings reported in the literature for metal substrates $[10,11]$. In this case the limiting effect of voltage on coating growth was detected at higher voltage levels because of the stronger grounding ability of metal substrate (70 to $80 \mathrm{kV}$ ) [11]. In contrast to metal substrates [10,11], there were no proper back ionization phenomena affecting electrostatic spray deposition (ESD) onto plastic substrate. In fact, even if the strength of the electric field and the negative charge in the uncured powder film increased in accordance with applied voltage, a very weak positive "mirror charge" inside the tiny copper layer arose. Therefore, even if the strength of the electric field might build to a point where it began to ionize the air trapped between the powder particles, the movement of resulting charged particles was limited by the lack of relatively positive ground. This reduces the detachment effect of the uncured layer of polymeric powders from the plastic (PA66) substrates. On the other hand, an increase in feeding pressure and in auxiliary pressure respectively caused an increase and a diminution of coating thickness (Fig. 6-a). In fact, these parameters acted straight on the other active force involved in electrostatic spray deposition (ESD), that is, the aerodynamic force. Increasing the feeding pressure concurrently increases both the amount of powder coming out from the gun and strengthens the aerodynamic push toward the grounded plastic substrate exerted on the powder by compressed air. Furthermore, decreasing the auxiliary pressure resulted in a much less spread cloud of polymeric powders, and the aerodynamic push of compressed air on polymeric powders was consequently more focused toward the grounded substrate. Therefore, thicker coatings could be achieved by increasing both the feeding pressure and decreasing the auxiliary pressure, in agreement with models and experimental findings reported in literature $[12,13]$.

Fig. 6-b reports the MEP of average roughness for hybrid epoxy-polyester powder. Trend in average roughness was influenced by the same electrical phenomena, which determined the coating thickness trend. In particular, if too low a voltage was used $(30 \mathrm{kV})$, a scant film of polymeric powder was deposited onto plastic substrate with poor finishing quality. The surface finish achieved was the best when larger voltages were selected $(50 \mathrm{kV})$. Nonetheless, further increase in voltage concurrently gives rise to electrical repelling effects inside the film of polymeric powder and detachment or displacement of polymeric powders from the plastic substrate occurs suddenly causing the surface finishing to deteriorate. However, even aerodynamic issues could influence the surface finishing. Too low a feeding pressure (1.5 bar) or too high an auxiliary pressure (1.5 bar) should be avoided. In fact, such operating levels produced very thin and uneven coating thickness, hence causing the worst PA66 substrate surface finish (Fig. 6-b). This agreed with indications reported in the literature where to achieve an acceptable level of surface finish uniformly distributed all over the surface, a film thickness of at least $40 \mu \mathrm{m}$ is suggested for hybrid powder [16].

The significance of all the operating parameters on coating thickness of epoxy-polyester film was confirmed by ANOVA. The corresponding Fisher's factors and $P$-values are summarized in Table 3 (first two columns), which reports the ANOVA results for all the films. No strong interaction effects between the operative variables were evident. On the contrary, the effects of interaction were found to influence the average roughness of epoxy-polyester films significantly (Table 4).

The influence of voltage was different on the hybrid epoxypolyester powder with metallic flakes. The coating thickness trends of metallic films were not as strongly influenced by electrical effects, as can be deducted from the trends in Fig. 6-c or from comparing Fisher's factors and $P$-values reported for the different films in the first row of Table 3 . This is probably caused by the presence of metallic flakes, which being

Table 4

ANOVA table for average roughness for all the deposited films

\begin{tabular}{|c|c|c|c|c|c|c|}
\hline \multirow[t]{2}{*}{ Source } & \multicolumn{2}{|c|}{$\begin{array}{l}\text { Epoxy- } \\
\text { polyester }\end{array}$} & \multicolumn{2}{|c|}{$\begin{array}{l}\text { Metallic } \\
\text { epoxy- } \\
\text { polyester }\end{array}$} & \multicolumn{2}{|l|}{ Epoxy } \\
\hline & $\mathrm{F}$ & $\mathrm{P}$ & $\mathrm{F}$ & $\mathrm{P}$ & $\mathrm{F}$ & $\mathrm{P}$ \\
\hline Voltage, $\mathrm{kV}$ & 4.33 & 0.01 & 0.16 & 0.92 & 9.15 & 0.00 \\
\hline Feed. Pres., bar & 3.83 & 0.03 & 13.02 & 0.00 & 9.25 & 0.00 \\
\hline Aux. Pres., bar & 16.75 & 0.00 & 40.01 & 0.00 & 30.06 & 0.00 \\
\hline Voltage, $\mathrm{kV}^{*}$ Feed. Pres., bar & 2.50 & 0.03 & 1.31 & 0.26 & 2.02 & 0.07 \\
\hline Feed. Pres., bar* Aux. Pres., bar & 1.95 & 0.11 & 2.88 & 0.03 & 4.52 & 0.00 \\
\hline Voltage, $\mathrm{kV}^{*}$ Aux. Pres., bar & 2.41 & 0.03 & 0.73 & 0.62 & 1.48 & 0.19 \\
\hline
\end{tabular}


(a)

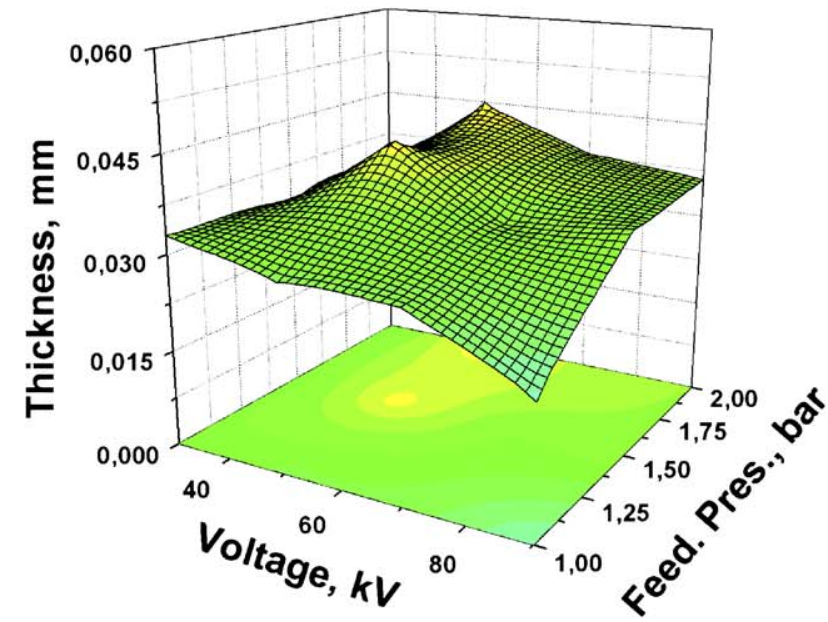

(c)

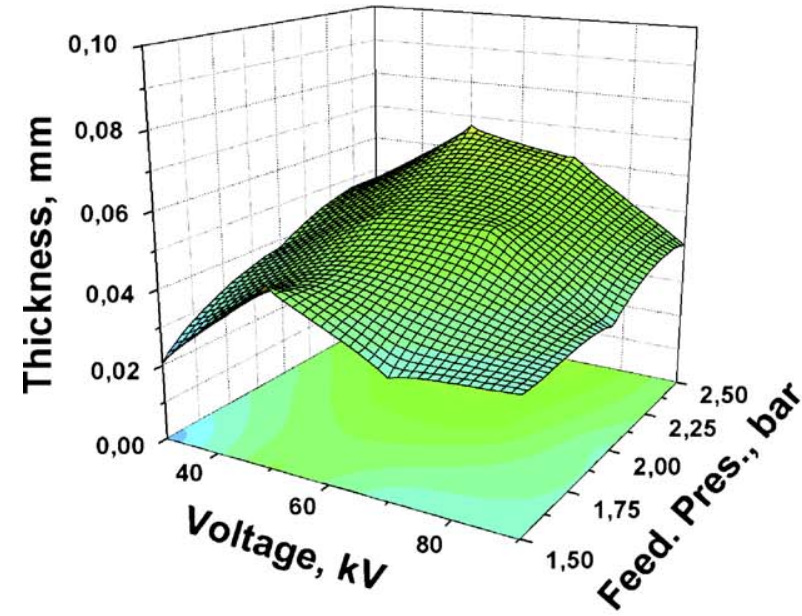

(e)

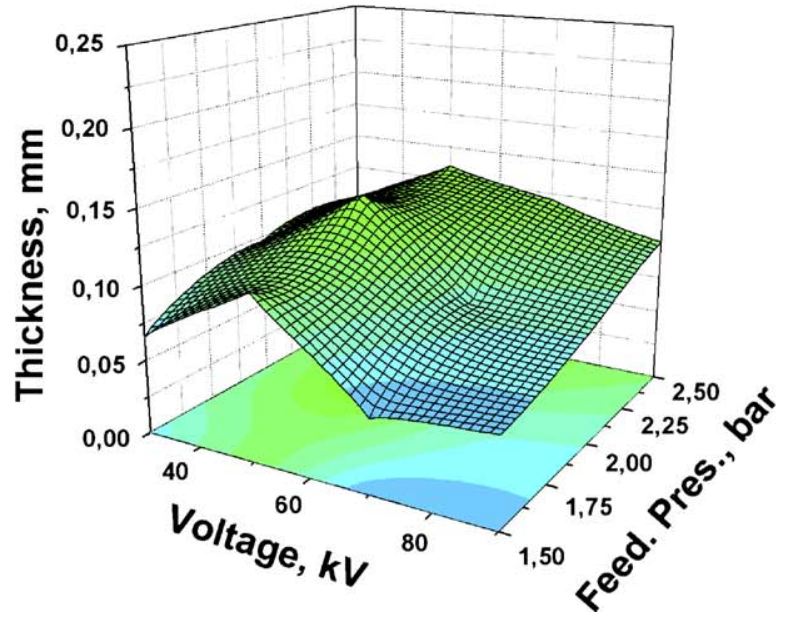

(b)

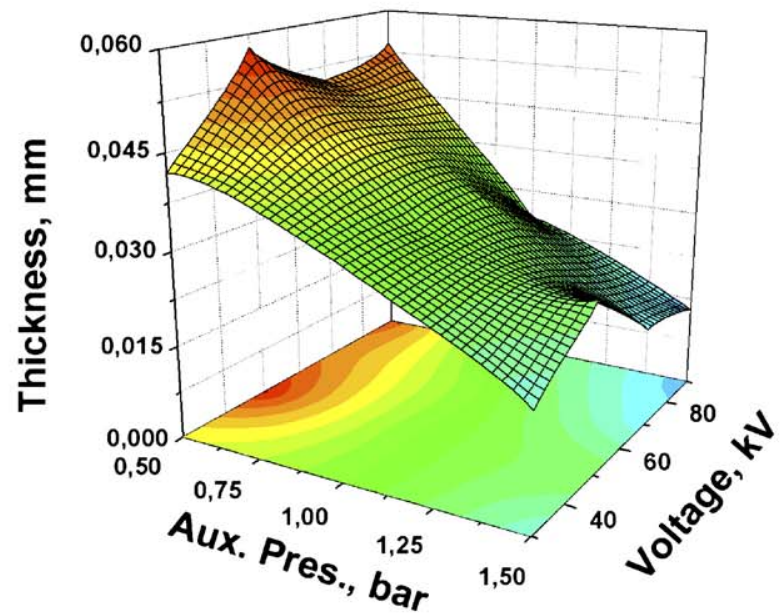

(d)

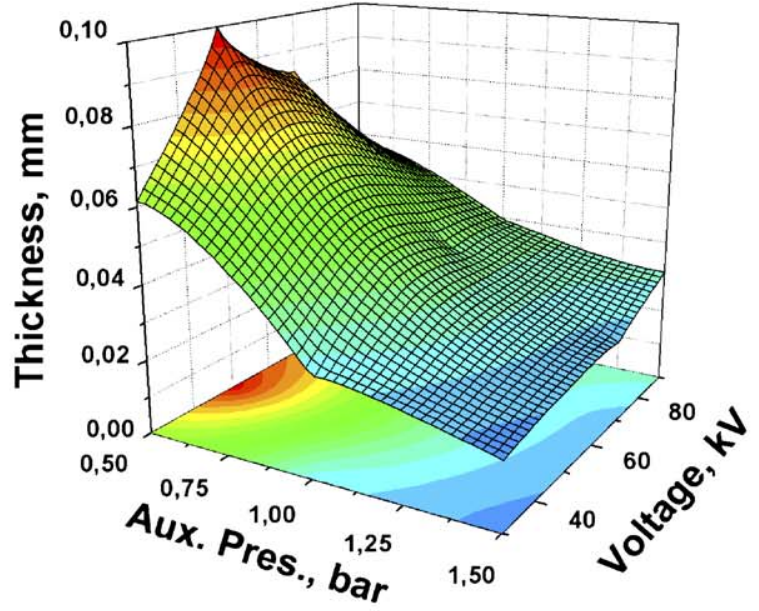

(f)

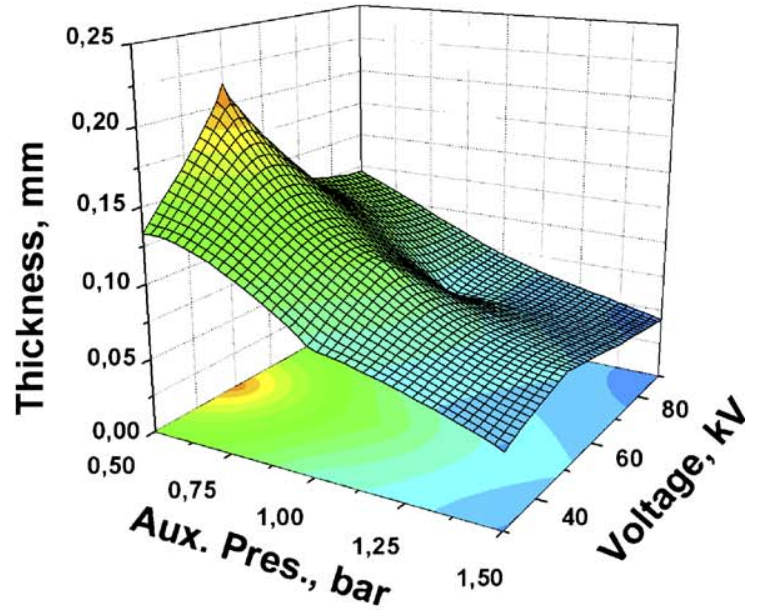

Fig. 7. Coating thickness vs. operating parameters: $(a-b)$ epoxy-polyester powder, (c-d) epoxy-polyester powder with metallic flakes, (e-f) epoxy powder. 
(a)

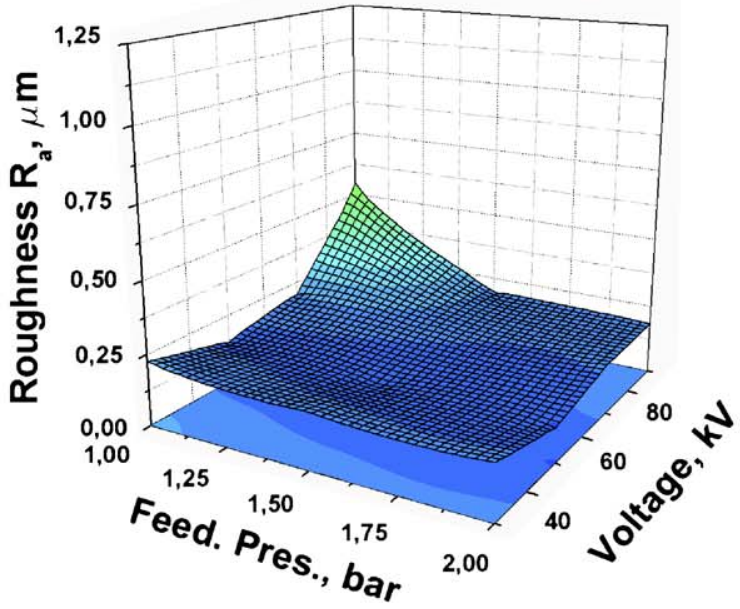

(c)

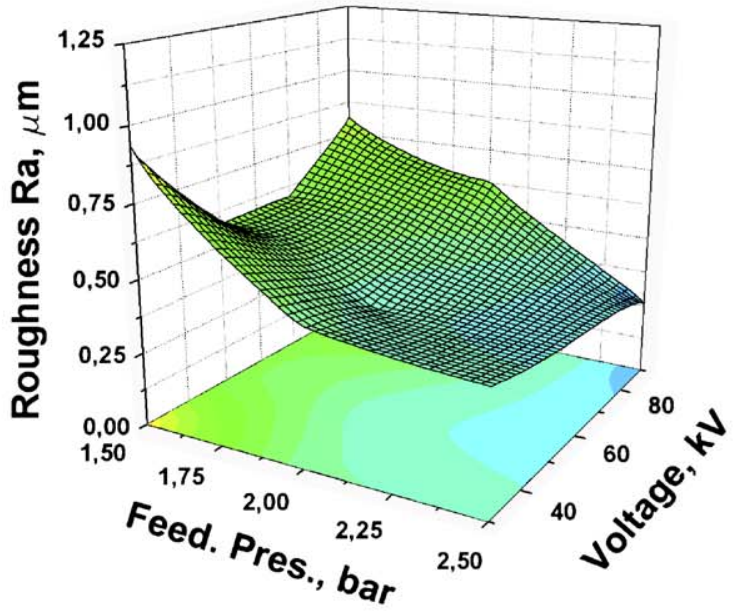

(e)

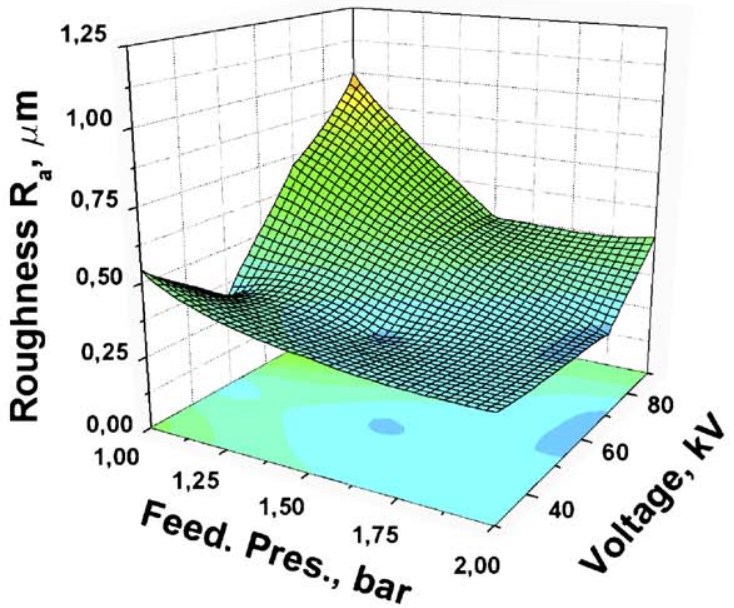

(b)

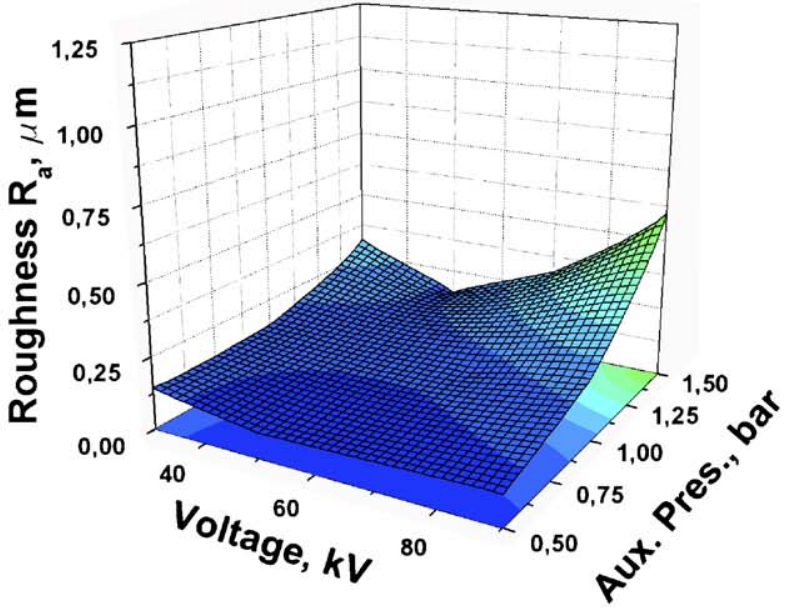

(d)

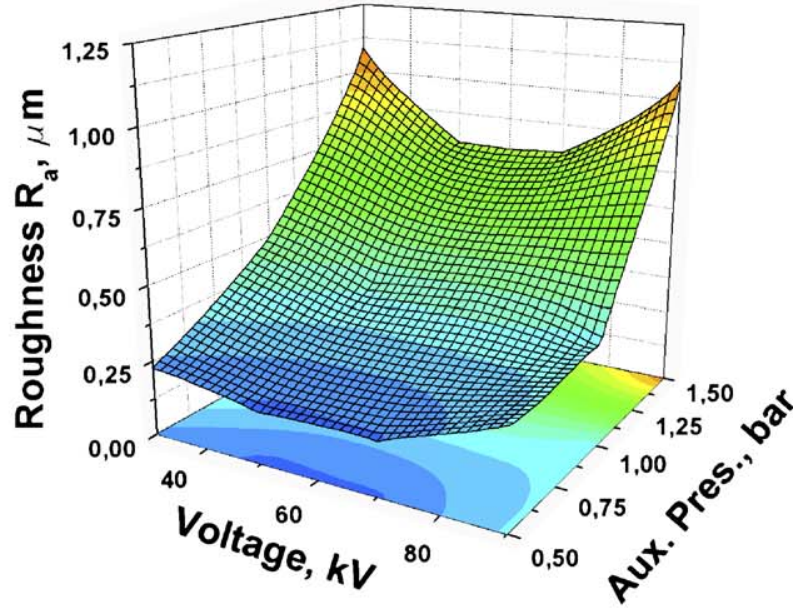

(f)

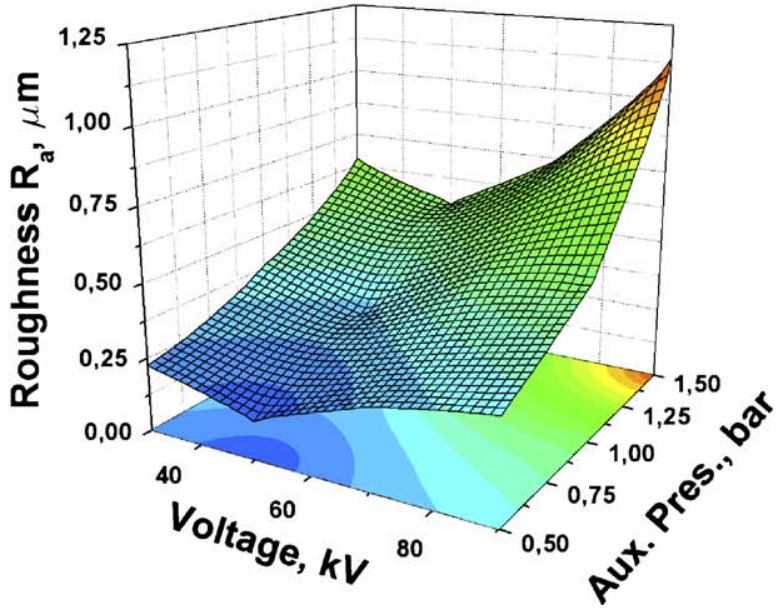

Fig. 8. Average roughness vs. operative parameters: (a-b) epoxy-polyester powder, (c-d) epoxy-polyester powder with metallic flakes, (e-f) epoxy powder. 
conductive could simplify the electrical discharge of polymeric powder once deposited onto plastic substrate. As can be seen from Fig. 6-d and Fisher's factor of 0.16 or $P$-value of 0.92 reported in Table 4, even surface finish of metallic films is subject to minor changes when voltage is varied. In fact, metallic flakes rapidly reach a high temperature in the oven and act as additional promoting centers for curing process [14-16], thus assisting film curing. This results in a good flow of polymeric film in all conditions, which generates flatter morphologies.

Epoxy films respond to voltage in a different way. Larger coating thickness was obtained when epoxy powder was applied (Fig. 6-e). Such coatings are usually employed for protective or insulation purposes [3]. Subsequently, the curing process was more complicated and the resulting surface finish was usually worse than those achieved for hybrid epoxypolyester powders, as the data in Fig. 6-f show. Moreover, coating thickness and average roughness values were found to be very sensitive to variations in all the operating parameters, as Fisher's factors and $P$-values reported in the last two rows of Tables 3 and 4 also confirm.

\subsection{Electrostatic spray deposition (ESD): process map}

Figs. 7 and 8 report the process maps for coating thickness and average roughness for all the polymeric powders used according to voltage and feeding pressure, and voltage and auxiliary pressure, respectively. Figs. 7-a and 8-a show that largest coating thickness and best surface finish were achieved using a voltage of around $50 \mathrm{kV}$ and a feeding pressure in the range of 1.5 to 2.0 bar. Values of coating thickness very close to $50 \mu \mathrm{m}$, which is the most widely used thickness for this kind of coating [16], could be easily attained under these process conditions. With regard to average roughness, values as low as $0.1 \mu \mathrm{m}$ could be achieved, hence allowing a glossy surface finish with a satisfying aesthetic aspect lacking anomalies such as voids, pinholes, and micro-craters. Figs. 7-b and 8-b take the effect of auxiliary pressure into account. As can be seen, too large a value of auxiliary pressure resulted in scant coating thickness and, subsequently, poor surface finish. Therefore, auxiliary pressure lower than 1.0 bar achieves the best overall coating performance. Similar considerations apply to hybrid epoxy-polyester powder with metallic flakes (see Fig. 7-c and d

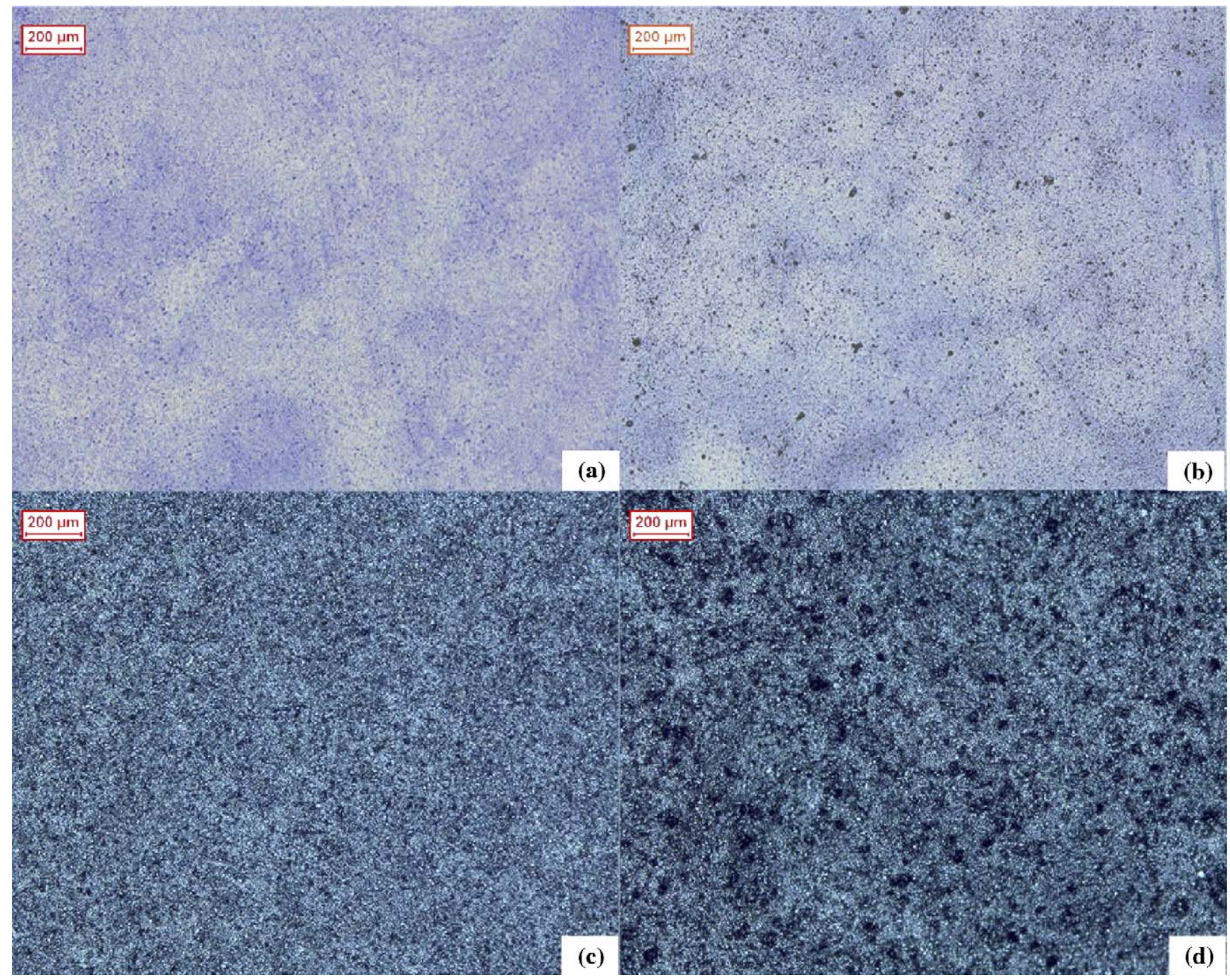

Fig. 9. Images of polymeric film after curing process: (a-b) epoxy-polyester powder; (c-d) epoxy-polyester powder with metallic flakes. 


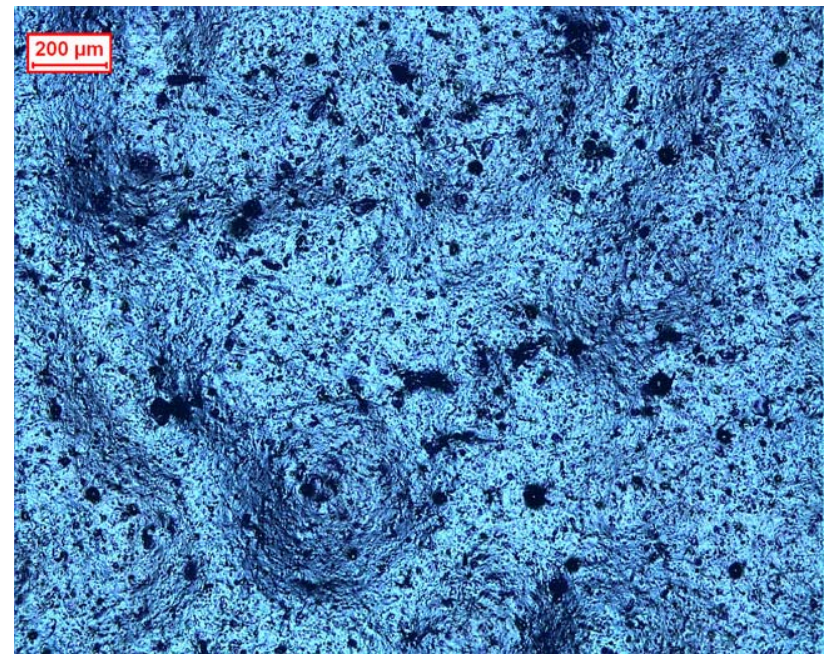

Fig. 10. Image of polymeric film after curing process: epoxy powder.

for coating thickness trends and Fig. 8-c and d for average roughness trends). When a voltage of $50 \mathrm{kV}$ was coupled with feeding pressure of 2.0 bar and auxiliary pressure lower than 1.0 bar, coating thickness of approximately $60-70 \mu \mathrm{m}$ and average roughness as low as $0.3 \mu \mathrm{m}$ could be achieved. These values agree very well with typical specifications reported in the literature for paints [11], confirming the effectiveness of electrostatic spray deposition (ESD) as a coating technique even for plastic substrate.

As support evidence for previous experimental findings, Fig. 9-a to d show the aesthetic aspects of epoxy-polyester and of epoxy-polyester with metallic flake films. In particular, images in panel (a) and in panel (c) exhibit the aesthetic aspects achievable for best settings of operating parameters. On the contrary, panel (b) and panel (d) displays defects and alterations such as craters, voids, and pinholes, typical of negative electrical phenomena when too high a voltage was set.

A different behavior was exhibited by epoxy powder (see Fig. 7-e and $\mathrm{f}$ for coating thickness trends, and Fig. 8-e and $\mathrm{f}$ for average roughness trends). If a voltage of $50 \mathrm{kV}$ was coupled with feeding pressure of 2.0 bar and auxiliary pressure lower than 1.0 bar, coating thickness of approximately $150 \mu \mathrm{m}$ and average roughness of $0.3-0.4 \mu \mathrm{m}$ could be achieved. However,

Table 5

Surface morphology: comparison of epoxy-polyester film, epoxy-polyester powder with metallic flakes film, and epoxy film

\begin{tabular}{|c|c|c|c|}
\hline \multirow{2}{*}{$\begin{array}{l}\text { Surface } \\
\text { status }\end{array}$} & \multicolumn{3}{|l|}{ Coating material } \\
\hline & Epoxy-polyester & $\begin{array}{l}\text { Epoxy-polyester with } \\
\text { metallic flakes }\end{array}$ & Epoxy \\
\hline Shrinkage & Minimised & Minimised & Present \\
\hline Voids & Minimised & Present & Present \\
\hline Pin holes & Minimised & Present & Relevant \\
\hline $\begin{array}{r}\text { Orange } \\
\text { peels }\end{array}$ & Minimised & Minimised & Relevant \\
\hline $\begin{array}{l}\text { Edge } \\
\text { cover }\end{array}$ & Minimised & Minimised & Maximised \\
\hline
\end{tabular}

even if the best operating settings were found to be close to those of epoxy-polyester powders, a poor aesthetic aspect was achieved under all the investigated process conditions. The scant aesthetic aspect of epoxy films can be ascribed to the type of raw material, which typically requires a substrate preheating before the deposition process to improve its flowing capability $[17,18]$. As a consequence, the epoxy film was not able to
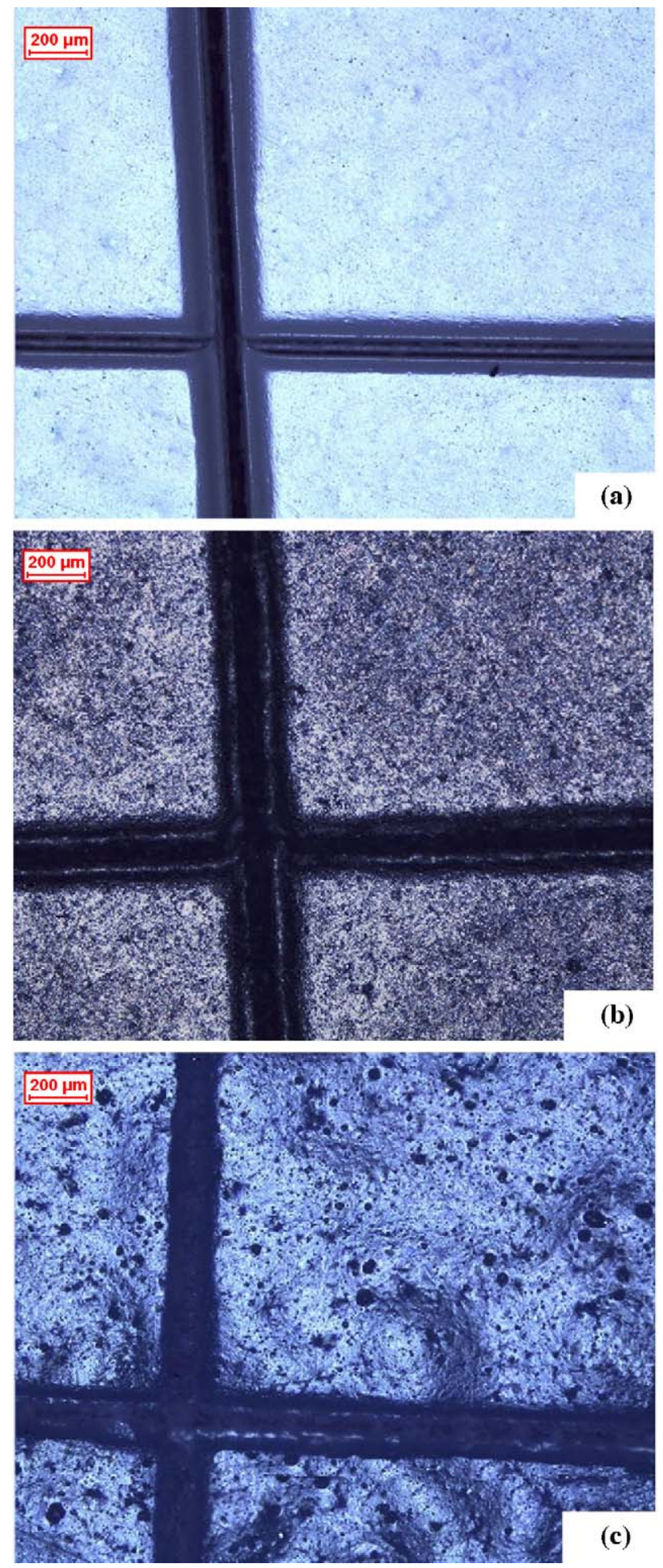

Fig. 11. Scratch test: (a) epoxy-polyester powder, (b) epoxy-polyester powder with metallic flakes, (c) epoxy powder. 
stretch out during curing process, hence giving rise to a coating characterized by remarkable wrinkleness (Fig. 10). However, the comparison of morphological characteristics of all three films examined contained in Table 5, and Fig. 11-a to c which display the results of scratch tests on each different polymeric film, show that no film delamination or cracks occurred. So there was always good adhesion of polymeric film onto plastic substrate, thereby confirming the effectiveness of the prepaint treatments in making the plastic (PA66) substrate ready for electrostatic spray deposition (ESD).

\subsection{The influence of exposure time}

The influence of exposure time on coating thickness and average roughness trends was studied under standardized test conditions. Voltage, feeding pressure, and auxiliary pressure were set at their best levels (respectively, $50 \mathrm{kV}, 2.0$ bar, and 1.0 bar), in agreement with indications provided by previous experimental findings. Fig. 12 displays the trend of coating thickness according to exposure time for each polymeric powder investigated. All the polymeric films behaved similarly. A quick growth of coating thickness was measured in short order (up to $6 \mathrm{~s}$ as exposure time). Then, since the self-limiting effect of electrostatic powder coating became stronger, a slowdown in coating thickness growth occurred (from 6 to $9 \mathrm{~s}$ as exposure time), followed by a reduction of coating thickness (for an exposure time greater than $9 \mathrm{~s}$ ) was detected. This result agreed with experimental findings reported in the literature for metal substrates [11], even though the drop in coating thickness on metal substrates was found for larger exposure time. In fact, as outlined above, the progressive deposition of electrically charged powder onto plastic substrate resulted in a 'saturation effect.' In fact, it was found that the tiny copper layer was not able to discharge the electrical charge from the polymeric powder when thick coatings were applied and, above all, to ground the more external layers. This consequently activated repelling effects between deposited powder particles, thus creating an electrical barrier to incoming powders, and resulting in detachment of the already deposited but not adhered powder and displacements of the powder itself inside the polymeric

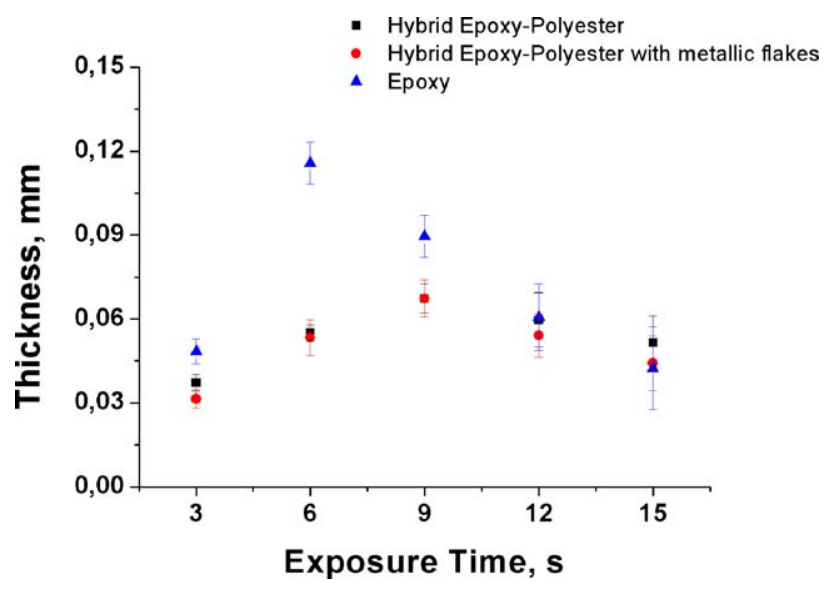

Fig. 12. Influence of exposure time: coating thickness.

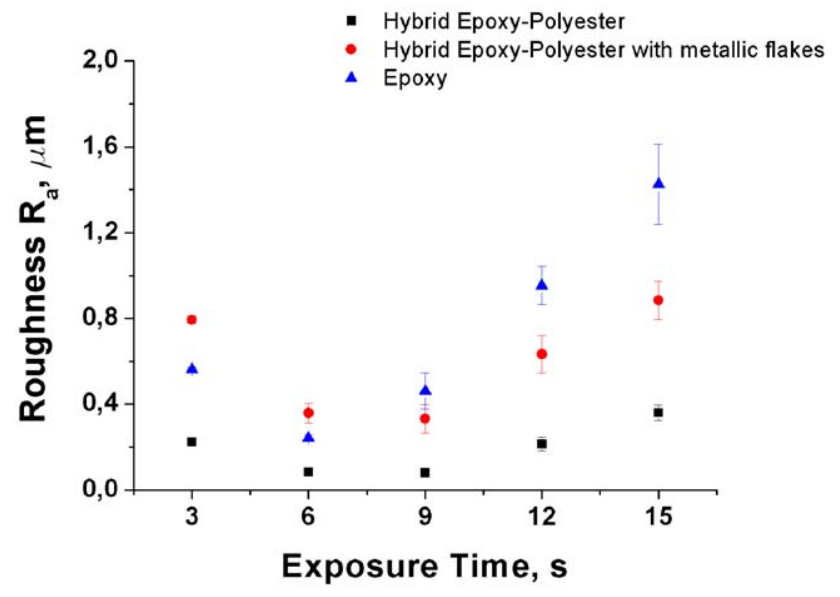

Fig. 13. Influence of exposure time: average roughness.

layer. Slight back ionization effects could be also inferred as a result of the progressive ionization of the air trapped between the deposited polymeric layers. More marked effects in terms of coating thickness drop after the 'saturation effect' were noted for epoxy film, being characterized by faster increase in coating thickness and, therefore, subjected to stronger negative electrical phenomena.

Fig. 13 displays the trend of average roughness for each polymeric powder investigated according to exposure time. Consistent trends of average roughness with previous considerations were found. In particular, as a result of negative electrical phenomena, after an exposure time of 6-9 s, a sudden drop in surface finishing was observed. This was in agreement with results reported in the literature for metal substrates [11], even though the deterioration of surface finish using metal substrates occurred after higher exposure time. However, the deterioration of surface finishing was found to be more critical for epoxy film. This was ascribed to stronger negative electrical phenomena characterizing the later phases of epoxy powder deposition process onto plastic substrates due to the coating thickness values being too large.

\section{Conclusions}

The effects of electrical and aerodynamic process parameters on electrostatic spray deposition (ESD) of polymeric powder (epoxy-polyester, metallic epoxy-polyester and epoxy) onto thermoplastic (PA66) substrate were researched. Furthermore, a novel and unprecedented prepaint treatment based upon a low speed cold spray of fine copper powders was developed.

Low speed cold spray of copper powders was found to coat plastic substrates with an even and well-adherent copper thin coating in short order. The copper film, changing the surface resistivity of plastic substrates, made them conductive, and subsequently ready for electrostatic spray deposition (ESD). As a result, electrostatic spray deposition (ESD) could successfully coat the plastic substrates using all the different powders studied, and without further pretreatment.

Regarding the analysis of process parameters, it was found that: (i) too low a level of voltage $(30 \mathrm{kV})$ gave rise to poor 
coating thickness because of the weak electrical field established; (ii) too high a level of voltage (from $70 \mathrm{kV}$ ) had to be avoided because rapid saturation of the thin copper film capability to discharge the powder deposited onto plastic substrates occurred, and consequently caused a detrimental repelling effects between the deposited powder particles; (iii) too low a value of aerodynamic push (i.e. feeding pressure $<2$ bar and auxiliary pressure $>1$ bar) had to be avoided so as to improve the transfer efficiency of the polymeric powder from the gun toward the grounded plastic substrate; (iv) exposure time in the range of 6-9 s produced the best overall performance.

Differences between the investigated polymeric films were found. Metallic epoxy-polyester was found to be less sensitive to voltage. In connection with this, metal flakes were thought to increase film conductivity, hence contributing to the release of the electrical charge from the polymeric powder once deposited on the substrate. Epoxy film produced the larger coating thicknesses for which it was designed. Accordingly, electrical problems developed more quickly and surface finish deteriorated and the experimental response to parameter settings was highly sensitive.

Finally, it is worth noting that with the prepaint and application techniques employed being absolutely solventfree, the developed painting facility can be operated using basic equipment and without any particular operator safety precautions and environmental impacts. In addition, both cold spray and electrostatic spray deposition (ESD) can be scaled-up and fully automated for a moderate cost, thus making this painting facility an effective alternative to traditional systems.

\section{References}

[1] F. Reidenbach, ASM Metal Handbook, Tenth edition, Surface Cleaning, Finishing, and Coating, vol. 5, 1994.

[2] Painting Guide, GE Plastics, 1998.

[3] K.D. Weiss, Prog. Polym. Sci. 22 (1997) 203.

[4] N. Foulon Belkacemi, R. Coelho, J. Phys., D, Appl. Phys. 28 (1995) 1001.

[5] Y. Tsuchiya, K. Akutu, A. Iwata, Prog. Org. Coat. 34 (1998) 100.

[6] D. Kumar, R.C. Sharma, Eur. Polym. J. 34 (8) (1998) 1053.

[7] R. Strumpler, J. Glatz-Reichenbach, J. Electroceram. 3 (4) (1999) 329.

[8] M. Barletta, V. Tagliaferri, Int. J. Mach. Tools Manuf. (May 2005) 1.

[9] M. Barletta, G. Costanza, R. Polini, Thin Solid Films (October 2005).

[10] M. Barletta, V. Tagliaferri, Surf. Coat. Technol. (February 2005) available on www.sciencedirect.com.

[11] M. Barletta, V. Tagliaferri, Surf. Coat. Technol. (April 2005) available on www.sciencedirect.com.

[12] Q. Ye, J. Domnick, Powder Technol. 135-136 (2003) 250.

[13] F. Wang, R. Martinuzzi, J. Jing-Xu Zhu, Powder Technol. 150 (2005) 20.

[14] M. Gedan-Smolka, D. Lehmann, S. Cetin, Prog. Org. Coat. 33 (1998) 177.

[15] R.B. Prime, Thermal Characterization of Polymeric Materials, Academic Press, New York, 1981.

[16] M. Barletta, Ph.D. Thesis, D.I.M., University of Rome "Tor Vergata," 2003.

[17] A.C. Rouw, Prog. Org. Coat. 34 (1998) 181.

[18] D.C. Andrei, J.N. Hay, J.L. Keddie, R.P. Sear, S.G. Yeates, J. Phys., D, Appl. Phys. 33 (2000) 1975. 